\title{
ANÁLISE DO PROCESSO DE TRABALHO DA ENFERMAGEM NA UNIDADE DE TERAPIA INTENSIVA ${ }^{1}$ ANALYSIS OF THE NURSING WORK PROCESS IN THE INTENSIVE CARE UNIT ANÁLISIS DEL PROCESO DE TRABAJO DE LA ENFERMERÍA EN LA UNIDAD DE CUIDADOS INTENSIVOS
}

\author{
Leandro Barbosa de Pinho', Silvia Maria Azevedo dos Santos ${ }^{3}$ Luciane Prado Kantorskit
}

\begin{abstract}
${ }^{1}$ Recorte da Dissertação de Mestrado intitulada "O cuidado de enfermagem na Unidade de Terapia Intensiva: contradições entre o discurso e a prática profissional”, apresentada ao Programa de Pós-Graduação em Enfermagem (PEN) da Universidade Federal de Santa Catarina (UFSC), para obtenção do título de Mestre em Enfermagem.

${ }^{2}$ Enfermeiro. Doutorando em Enfermagem Psiquiátrica da Escola de Enfermagem de Ribeirão Preto da Universidade de São Paulo. Professor Assistente da Universidade Federal de Mato Grosso. Mato Grosso, Brasil.

${ }^{3}$ Enfermeira. Doutora em Educação. Professora do Departamento de Enfermagem e do PEN/UFSC. Santa Catarina, Brasil.

${ }^{4}$ Enfermeira. Doutora em Enfermagem. Pesquisadora do Conselho Nacional de Desenvolvimento Científico e Tecnológico. Professora da Faculdade de Enfermagem e Obstetrícia da Universidade Federal de Pelotas. Rio Grande do Sul, Brasil.
\end{abstract}

PALAVRAS-CHAVE: Cui- RESUMO: Este estudo pretende conhecer a dinâmica do processo de trabalho da enfermagem na Unidade dados intensivos. Trabalho. de Tratamento Intensivo de um hospital de Santa Catarina, apontando fragilidades, potencialidades, Cuidados de enfermagem. limitações e contradições veladas ou reveladas nos instrumentos utilizados pelos enfermeiros. O referencial teórico-filosófico que orientou essa pesquisa foi baseado nas concepções marxistas e gramscianas sobre processo de trabalho. Trata-se de uma pesquisa qualitativa, de orientação dialética, onde utilizamos entrevistas semi-estruturadas aplicadas a sete enfermeiros, além de observações de campo e análise documental. Os dados coletados foram analisados segundo a análise de conteúdo. Os resultados ressaltam a utilização de variáveis tecnológicas centradas num modelo médico-hegemônico, responsáveis pelo fortalecimento de atividades parcelares e fragmentadas. Observamos o predomínio de tecnologias pouco centradas nas relações entre sujeitos. Constatamos que a unidade parece criar uma oportunidade de discutir e compreender como as práticas dos sujeitos produzem-reproduzem efeitos e deslocamentos no cotidiano assistencial dos serviços e nas relações interpessoais.

KEYWORDS: Intensive care. ABSTRACT: The study seeks to examine the dynamics of the nursing work process in the Intensive Work. Nursing care. Care Unit, pointing out weaknesses, potentialities, limitations, and veiled/unveiled contradictions in the instruments utilized by nurses. This is a qualitative investigation, with dialectic orientation, which takes place in an Intensive Care Unit of a hospital in Santa Catarina, Brazil. We use semi-structured interviews applied to seven nurses, with participatory observation and documentary analysis. The theoretical-philosophical references are the Marxist and Gramscian conceptions of the work process. The results reinforce the use of technological variables centered on a medical-hegemonic model, responsible for the strengthening of parceled and fragmented activities. We observe the predominance of technologies originated from the evolution of science and little- centered on the relationships between citizens. We find that the unit seems to create an opportunity to discuss and to comprehend how the professional practices produce-reproduce effects and displacements in the day-to-day care of services and interpersonal relationships.

PAlabras Clave: Cuidados intensivos. Trabajo. Atención de enfermería.
RESUMEN: El presente estudio pretende conocer la dinámica del proceso de trabajo de enfermería en la Unidad de Cuidados Intensivos, señalando fragilidades, potencialidades, limitaciones y contradicciones veladas o reveladas en los instrumentos usados por los enfermeros. Se trata de una investigación cualitativa, de orientación dialéctica, realizada en una Unidad de Cuidados Intensivos de un hospital de Santa Catarina. Para la investigación, utilizamos entrevistas parcialmente estructuradas con siete enfermeros, además de observaciones de campo y análisis documental. El referencial teórico-filosófico que orientó el análisis está basado en conceptos marxistas y gramscianos sobre el proceso de trabajo. Los resultados obtenidos resaltan el manejo de variables tecnológicas de un modelo médico-hegemónico, fortaleciendo las actividades parcelares y fragmentadas. Observamos la utilización de tecnologías originadas por la evolución de la ciencia y poco centradas en las relaciones entre sujetos. Constatamos que la Unidad parece crear oportunidades de discutir y comprender cómo las prácticas de los sujetos producen-reproducen efectos y modificaciones en el contexto de los servicios y en las relaciones interpersonales.
Leandro Barbosa de Pinho

Endereço: Av. Fernando Osório, 471, Bl. E, Ap. 202

96.055-000 - Três Vendas, Pelotas, RS, Brasil.

E-mail: lbpinho@uol.com.br
Artigo original: Pesquisa

Recebido em: 29 de janeiro de 2007 Aprovação final: 28 de setembro de 2007 


\section{INTRODUÇÃO}

A unidade de terapia intensiva compreende um conjunto de estratégias de atendimento e cuidado centradas na recuperação/reabilitação do indivíduo com problemas graves de saúde, com riscos imediatos/mediatos de morte. Por esse motivo, distintas aberturas teóricas, instrumentais e técnicas aparecem como dispositivos incorporados aos processos de trabalho das equipes nesses setores. ${ }^{1-3}$

A realidade assistencial de práticas de saúde e de cuidado na Unidade de Terapia Intensiva (UTI), por sua complexidade, pode compor um arsenal tecnológico que reflita o saber operante e a prática destinada à recuperação do indivíduo a partir de uma concepção ampliada (ou deslocada) de saúde e doença. Quando referimo-nos a isso, queremos dizer que, nessas unidades, saúde e doença estão em ínfima disposição relacional e, por vezes, podem ser confundidas com práticas que ao finalizarem (teoricamente) em saúde, invariavelmente destinam-se ao compromisso de restabelecer o indivíduo de seu quadro de doença.

Nesse sentido, embora as práticas e os saberes com relação ao processo saúde-doença na história sejam eles próprios motivos de conflitos e rupturas, nas unidades de atendimento intensivo a lógica $\mathrm{da}$ produção de saúde parece seguir os padrões de um modelo de assistência que defende uma produção baseada no modelo biomédico e tecnologizante por natureza. É claro que isso tem sua razão de acontecer. Não seria por acaso que a própria medicina, enquanto profissão que se ampara no saber clínico para reabilitar/curar sujeitos e que se desenvolve plenamente no modo de produção capitalista, ${ }^{4-5}$ não pudesse orientar saberes e práticas julgadas intensivas, quando, não muito, imediatas, para retardar a morte e/ou a situação de invalidez permanente. Portanto, é necessário que os processos de trabalho dos profissionais comecem a contemplar a lógica da produção de saúde a partir da doença não somente, mas também da dimensão ontológica e existencial dos sujeitos, o que parece não ser uma tarefa fácil em se tratando de uma saúde tecnologizada e centrada na lógica biomédica e fragmentária. ${ }^{6}$

Diante disso, procuramos conhecer a dinâmica do processo de trabalho da enfermagem na UTI. Pretendemos apontar fragilidades, potencialidades, limitações e contradições que se revelam (ou são veladas) nos instrumentos do processo de trabalho da enfermagem na unidade.

\section{REFERENCIAL TEÓRICO-FILOSÓFICO}

A construção da enfermagem, como prática social, ultrapassa as relações entre os sujeitos, para a promoção do cuidado integral, relacional e intersubjetivo. Essa construção pode ser observada como um conjunto de características complexas, que intercalam as subjetividades das pessoas com um dado momento histórico-político-social e, no nosso caso, de saúde. Nesse sentido, utilizamos algumas das idéias marxistas e gramscianas sobre as condições materiais da existência e sobre os processos de trabalho, para embasar as discussões sobre os conhecimentos teóricos e práticos no ambiente da terapia intensiva.

A natureza faz parte da vida humana fornecendo ao homem os modos de produção já existentes, que são reproduzidos durante o processo de viver. Entretanto, os modos de produção disponíveis não se encerram apenas em uma mera reprodução da existência física dos sujeitos, já que todos eles demonstram ter uma maneira única de se manifestar, de recriar a vida, um modo de viver determinado. O homem depende das condições materiais de produção, ou seja, das relações entre os indivíduos para refletir o que ele é, fazer-se sujeito individual e coletivo, produzir as suas idéias e as suas representações, refletir a sua consciência, reescrever a sua história.?

Pensando o homem como um produto da história, poderíamos dizer que a história também é uma produção do homem, ambos em processo dialético de reconhecimento e transformação. O homem é um ser em processo, precisamente o processo de suas próprias vontades e atitudes. ${ }^{8}$ Nesse sentido, ao dominar a natureza construindo a sua vida social, produz a si mesmo, re-visita a sua existência, a sua realidade, a sua consciência, humanizando-se. As relações que ele estabelece com os meios de produção constroem a matéria, as relações humanas, sendo estas a base do movimento da vida e do coletivo. Por isso, o trabalho se constitui no princípio básico pelo qual ele produz/reproduz sua história, fazendo-se co-partícipe do mundo e das relações que o permeiam.

$\mathrm{O}$ trabalho corresponde à condição básica $\mathrm{e}$ fundamental de toda a vida humana, capaz de modificar a natureza, assim como a si mesmo perante ela. Para designar a importância que o trabalho desempenha na vida humana basta comparar as relações entre o homem e o macaco. O macaco e as outras espécies animais transformaram-se de acordo com a disponibilidade de meios de sobrevivência, 
ou seja, de adaptação à vida, nem sempre habitual, mas que sustentavam as necessidades mais imediatas do animal naquele momento. Essa realidade não poderia ser considerada como um trabalho, já que ela prescinde a elaboração de instrumentos. Com relação ao homem, quanto mais este se afastava para a elaboração de seus instrumentos de trabalho, mais se elevava sobre o reino animal. Isso quer dizer que o homem aprendia com a vida, ao contrário do macaco que se adaptava a ela. Portanto: "[...] só o que podem fazer os animais é utilizar a natureza e modificá-la pelo mero fato de sua presença nela. $\mathrm{O}$ homem, ao contrário, modifica a natureza e a obriga a servir-lhe, domina-a. E aí está, em última análise, a diferença essencial entre o homem e os demais animais, diferença que, mais uma vez, resulta no trabalho".9:6

O trabalho como fonte da vida humana e das relações sociais compreende duas formas tecnológicas $^{*}$ distintas, porém complementares de atuação: o trabalho morto e o trabalho vivo. O primeiro diz respeito ao conjunto de ferramentas e dispositivos analíticos e técnicos que "estão postos aí", ou seja, não podem ser modificados pelo trabalho vivo em ato, mas que já se constituíram em trabalho vivo, pois foram produzidos em outro processo de trabalho. Já o trabalho vivo corresponde à forma criadora de fazer, dotado de sentido pleno que possibilita re-significar, repensar e revitalizar formas de saber-fazer (ou tecnologias) no trabalho. No entanto, o trabalho morto é capaz de capturar o trabalho vivo a ponto de torná-lo inerte, sem ação, sem resolutividade, apenas dependendo do modo de como o instrumental é utilizado ou derivado para suprir as necessidades imediatas dos sujeitos. ${ }^{10}$

Sendo assim, entendemos que, dentro do contexto de trabalho na UTI, as relações sociais de produção que se estabelecem, entre os sujeitos e os instrumentos de trabalho que delas derivam, são destaques para o repensar do trabalho morto implicado no conjunto do processo e o trabalho vivo que, por ser dinâmico, pode ser revitalizado a partir das necessidades dos sujeitos. Tal justificativa pode antever, a partir dos instrumentos do processo utilizados pelos enfermeiros, as suas interpretações, os seus saberes operantes de fato e as práticas de saúde nesse espaço social.

\section{A TRAJETÓRIA METODOLÓGICA}

Por se tratar da investigação das particularizações, demandas e singularidades do contexto cotidiano do atendimento, optamos pela pesquisa qualitativa de orientação dialética. Essa associação pode dar conta de evidenciar as relações no mundo do trabalho na UTI, enquanto produção-reprodução das condições materiais da existência humana e das relações sociais. A abordagem dialética permitiu a discussão dos resultados a partir da negação dos mesmos, num movimento de tese-antítese-síntese, porém não com exclusão total nem parcial dos achados, porque fazem parte da construção do objeto cognoscente como um todo e da transformação da realidade social. ${ }^{11-12}$

Realizamos entrevistas semi-estruturadas com sete dos oito enfermeiros de uma UTI de um hospital do estado de Santa Catarina, segundo critérios previamente estabelecidos, tais como: tempo de trabalho, tipo de vínculo empregatício, disponibilidade para participação e autorização para publicação dos resultados. Os informantes também assinaram o Termo de Consentimento Livre e Esclarecido, conforme determina a Resolução 196/96 do Conselho Nacional de Saúde. ${ }^{13} \mathrm{O}$ projeto de pesquisa foi encaminhado e aprovado pelo Comitê de Ética em Pesquisa da instituição sob o $\mathrm{N}^{\circ}$ 200/05. O trabalho de campo ocorreu após essa aprovação, no período de junho e agosto de 2005.

Baseamo-nos na análise de conteúdo, fazendo leituras e releituras das entrevistas até chegar às categorias que mais apontassem o que estava sendo dito pelos informantes. $\mathrm{Na}$ etapa seguinte, quando iniciávamos a fazer inferências e interpretações, construímos eixos de discussão, sendo, neste estudo, abordada a questão dos instrumentos de trabalho e as concepções teórico-instrumentais e práticas de saúde na UTI a partir deles.

Utilizamo-nos também de observações de campo, realizadas durante todo o período de coleta de dados. Totalizamos 120 horas e registramos tudo que pudesse orientar nossa análise sobre o cotidiano do processo de trabalho na UTI, como a dinâmica do atendimento, as relações entre os sujeitos, os conflitos, saberes e práticas produzidas no contexto. Essas Notas de Observações (NO) foram importantes no momento de fazermos a análise dos

\footnotetext{
"A concepção de tecnologia adotada neste estudo considera não somente como um dispositivo fechado, mas também como certo "saber-fazer", um "ir-faz̧endo", que dá sentido à prática em saúde a partir de uma razão instrumental de trabalho. A tecnologia, enquanto participe de uma determinada realidade social, de um modelo tecnoassistencial, oportuniza a criação-recriação do trabalho a partir do saber operante do sujeito, contemplado nas dimensões técnicas e políticas que se revertem no cotidiano do contexto dos serviços de saúde. ${ }^{10}$
} 
dados coletados e nossas discussões porque, muitas vezes, ajudaram a compreender melhor o que estava sendo dito pelos sujeitos.

Realizamos consultas aos instrumentos que regulamentam a atuação de enfermagem na unidade, como os manuais de enfermagem, as planilhas de checagem de procedimentos, os prontuários, assim como os registros feitos diariamente pelos profissionais de enfermagem no cotidiano de seu processo de trabalho. O objetivo deste procedimento era o de poder complementar a apreensão do objeto de trabalho a partir da análise dos materiais concretos que são resultados de suas práticas na realidade. Os prontuários foram relativamente importantes para compor o arsenal deste estudo porque, nele, a enfermagem também faz suas anotações, principalmente nas situações de entrada, saída ou agravamento do quadro clínico.

Neste estudo, tivemos como foco central a leitura dos registros dos enfermeiros e o desenvolvimento da metodologia da assistência. Complementadas com as entrevistas, parecem fornecer um panorama do processo de trabalho na UTI. Entendemos que essa associação evidencia não somente as percepções dos enfermeiros acerca de seu próprio trabalho mas, a complexidade de organização e como essas percepções se materializam no cotidiano assistencial.

\section{RESULTADOS E DISCUSSÕES}

Optamos por apresentar os resultados de acordo com os instrumentos verificados, que compõem o processo de trabalho, seguido de suas discussões. Analisando dialeticamente os instrumentos de trabalho dos profissionais, em função das próprias relações sociais complexas que se estabelecem no setting, logo seria possível pensar na interminalidade de nossos posicionamentos. Assim, pensamos em trazer alguns questionamentos importantes que possam refletir acerca das concepções mais gerais do fenômeno para facilitar a compreensão e a leitura, ressalvadas as condições de que são interpretações discutíveis e não totalizadoras do conhecimento do espaço de atendimento.

\section{A organização dos registros de enfermagem}

A organização dos registros de enfermagem na UTI é hierarquizada conforme a própria constituição dos manuais e regimentos do hospital. A Diretoria de Enfermagem do hospital tem um "documento básico", contendo a filosofia e a metodologia da assistência escrito numa primeira versão em 1980. Existe também um manual que reúne as técnicas básicas de enfermagem e as atribuições funcionais da categoria, além de um complexo sistema teórico-conceitual para registros nos prontuários, baseado na metodologia de assistência de enfermagem de Wanda Horta ${ }^{14}$ e no modelo orientado para o problema do Sistema Weed.

A filosofia básica deste documento pretende respeitar o ser humano em sua integralidade, sem distinções, considerando a saúde um bem-estar do ser humano, em que ele está em equilíbrio consigo mesmo e com o meio ambiente. A enfermagem deve ser desenvolvida em equipe, com o compromisso do cooperativismo, sendo o enfermeiro responsável pela implementação dessa sistemática. A doença é apresentada como um processo de múltiplas causas, constituindo-se em uma intercorrência no ciclo vital.

Com relação ao prontuário, o documento básico destaca que ele utiliza como referência para os registros da assistência o "modelo orientado para o problema”. Os dados são registrados através das observações, com seus problemas específicos, sendo denominado "problema" tudo aquilo que requeira ou requereu assistência à saúde, além de afetar o bem-estar físico ou emocional de uma pessoa.

As notas de evolução são as avaliações diárias das condições do paciente e de suas respostas às prescrições. Nela constam os dados obtidos pelo enfermeiro através das visitas diárias, observações diretas, entrevistas com familiares, informações de outros profissionais, passagens de plantão, entre outros. O preenchimento desses registros baseia-se no formato "SOAP", assim distribuído: $\mathbf{S}$ - informações do paciente - o que ele sente, observa e/ou acredita ser, além de informações dos familiares e amigos; $\mathbf{O}$ - observações clínicas e resultados de exames; A - a análise explica os significados dos dados subjetivos. $\mathrm{O}$ profissional registra a opinião sobre como definir o problema em um maior grau de precisão, avaliando, ao mesmo tempo, a evolução da conduta e identificando novos problemas. Devem estar incluídas razões para manter, alterar ou abandonar uma conduta; P - a decisão sobre a conduta a ser tomada.

Existe também um Manual de Técnicas e Procedimentos de Enfermagem contemplando 136 itens, no qual está na sua quarta revisão, principalmente com vistas a providenciar a atualização de alguns procedimentos. 
Já a UTI não possuía até o final deste trabalho, um manual de procedimentos específico, sendo que o mesmo estava em processo de elaboração. Sendo assim, os enfermeiros adotavam o manual de técnicas e procedimentos da enfermagem, bem como os protocolos padronizados por doença ou quadro clínico, propostos pela Sociedade Catarinense de Medicina Intensiva e pelas equipes multiprofissionais.

A descrição inicial da documentação e dos registros de enfermagem, enquanto instrumentos do processo de trabalho podem ajudar no conhecimento de saberes e práticas operantes no mundo do trabalho da UTI. Como se pode notar, a filosofia que rege a organização teórico-metodológica desses registros está concentrada num modelo biomédico de saber-fazer. Pensando numa organização hospitalar, em que a rigidez de comando e estratificação do saber-fazer é evidente, é possível imaginar que a permanência desse modelo na prática de saúde, seja hegemônico e reinante. Isso se evidencia na adoção de alguns conceitos contraditórios, como por exemplo, o conceito de saúde que é definido como "bem-estar" enquanto o conceito de doença é definido como sendo "intercorrência".

O documento básico foi escrito na década de 80 , quando o processo saúde-doença ainda possuía uma visão centralizada na patologia, e não na complexidade de hoje, embora isso não seja motivo para que as práticas de saúde sejam concentradas neste último modo de saber-fazer. Mas isso será discutido a seguir, quando, ao se tratar da metodologia da assistência de enfermagem, será possível observar que as tecnologias utilizadas pelos enfermeiros tendem a reforçar (e não a superar) a manutenção do modelo biomédico.

\section{A metodologia de assistência}

Com relação ao modelo de Wanda Horta, que é o referencial teórico escolhido pela enfermagem do hospital para a prestação da assistência de enfermagem, é dividido em três grupos: necessidades psicobiológicas, psicossociais e psicoespirituais. Não pretendemos aqui expor em detalhes a metodologia de Wanda Horta, já que esgotaria nossa intenção de analisar o processo de trabalho na UTI, além de não ser este o objetivo. No entanto, os enfermeiros destacam-no como referencial básico para orientar a sua prática, como se pode ver nos fragmentos a seguir.

O referencial que eu uso é o da Wanda Horta, da teoria das necessidades humanas básicas, é o referencial teórico, básico e elementar pra mim [...] a parte prática eu procuro também usar ela. Na UTI a gente trabalha muito com as necessidades psicobiológicas. Então a gente vê o paciente e procura trabalhar a questão da vida, da prioridade, que nesse momento se prioriza a vida do paciente $\left(\mathrm{E}_{2}\right)$.

O nosso modelo eu acho que ele dirige mais pra tentar individualizar o cuidado. O modelo en acho que faz tu pensares um pouquinho mais, te obriga a olhar um pouquinho mais pro doente, teoricamente como todos os modelos. Embora ainda tenham essas questões religiosas e psicossociais, a gente atende parcialmente, porque a gente não é muito preparada pra isso, né? ( $\mathrm{E}_{4}$ ).

Claro que a gente ainda segue o modelo da Wanda Horta, de fazer, ajudar, orientar e encaminhar. Eu sigo essa linha, en me identifico mais com isso mesmo, mas trabalho em todos. Não escolbi um referencial que me oriente, eu circulo (E).

A questão da utilização de um referencial teórico para orientar a prática de cuidados na UTI merece destaque aqui. Um modelo de assistência, enquanto instrumento tecnológico do processo de trabalho auxilia na adoção de estratégias necessárias ao cumprimento das rotinas institucionais de práticas e de cuidados aos pacientes. Além disso, qualquer modelo, por mais fechado que seja, pode imprimir uma dinamicidade ao processo de trabalho, que se sobressaia às condições de atendimento padronizadas e rotineiras que freqüentemente acompanhamos nesses espaços sociais. Isso, por si só, pode significar uma ruptura com a clássica idéia de que um "modelo" serve para "orientar" e nada mais, quando na verdade ele representa um subsídio poderoso para que o profissional componha seus próprios instrumentos a partir de determinados indícios e necessidades. Exemplo disso é o de $\mathrm{E}_{6}$ quando fala que "circula" em possibilidades distintas de dispositivos tecnológicos.

Por outro lado, a dimensão teórica e conceitual da adoção de um "modelo" deve ser congruente com o pensamento e a filosofia de trabalho da equipe (o destaque é proposital), ou seja, o objeto de trabalho das pessoas deve ser o mesmo e ter as mesmas finalidades. Acreditamos que as diferenças e as multifuncionalidades dos registros dos enfermeiros têm sido fatos geradores de interpretações difusas, que, se não geram apenas confusões, geram idéias “imposicionais", como se o método fosse uma barreira à criatividade do enfermeiro e à adaptação de outras modalidades teóricas. As falas a seguir exprimem essa idéia.

Falando bem francamente, a gente usa mais esses modelos, eu acho, na prática, mais como uma regra da instituição. Eu 
não tenho muita consciência disso, e não vejo também muito nos outros colegas. A gente segue mais uma teoria mais como uma imposição da profissão. Acho que ainda a gente usa o método, o processo de forma inadequada... E também tem profissionais que devem ser envolvidos nisso que, às vezes, não conseguem se envolver muito por " $n$ " razôes, por culpa nossa ou não ( $\left.E_{4}\right)$.

Eu gosto muito da Leininger, que é o cultural. Trabalhava no Hospital Y com ele e comigo deu super certo. Exemplo: paciente não queria tomar banho todo o dia porque não estava acostumado, culturalmente não fazia parte dele, era respeitado isso e eu achava bem interessante, coisa que não é aqui [...] Eu não me sinto à vontade para isso, sabe? Por incrivel que pareça. Lá parece que eu tinha mais autonomia para fazer as coisas, aqui eu ainda não estou tão à vontade, eu sou nova ainda [...]. Eu não sei, eu não me sinto à vontade ainda para isso perante o grupo. Não sinto essa firmeza para estar me posicionando dessa forma, para estar providenciando esse tipo de comida, como eu fazia lá. Então eu meio que entro na onda, entendesse? ( $\left.E_{1}\right)$.

Eu vim de um hospitalprivado, ai aqui me deparei com essa metodologia da Wanda Horta e tive que me adaptar, não foi muito fácil, porque é uma coisa que você tem que registrar muito $\left(E_{5}\right)$.

Reportando-se ao fragmento de $\mathrm{E}_{4}$, percebe-se como as finalidades do trabalho na UTI, a partir dos modelos de assistência, são divergentes. Primeiro, porque o "modelo" é visto por ele apenas como uma "teoria", que é "imposta" pelo hospital. Nesse sentido, é possível observar que as concepções trazidas por $\mathrm{E}_{3}$ sobre seu trabalho na UTI parecem ter uma tradição centralizada na retórica da organização tecnológica vertical, quando o hospital (e não a enfermagem) seria o "controlador" do processo de trabalho na unidade.

Por outro lado, com relação às falas de $\mathrm{E}_{1}$ e de $\mathrm{E}_{5}$, é possível entender que o profissional "novo", que chega, parece ser "jogado" no sistema, aos poucos se adaptando e acompanhando-o. Sendo assim, aquela ruptura com o "referencial-padrão", a partir da liberdade de circularidade possível por outros instrumentos como referenciais para a prática, como referiu $\mathrm{E}_{6}$ anteriormente, não nos parece totalmente presente, cremos que mais por causa da adaptação do enfermeiro à realidade assistencial do que pela imposição institucional.

Especificamente com relação à fala de $\mathrm{E}_{4}$, o próprio fragmento de que "tive que me adaptar" remarca nossas preocupações. Embora pareça haver um esforço coletivo de priorizar a liberdade do saber operante na UTI (novamente lembramos aqui do fragmento de $\mathrm{E}_{6}$ ), o trabalhador, ao ser inserido em determinado processo de trabalho, tende a acompanhá-lo passivamente e a continuar assim, "identificando-se" com o sistema, já que a ruptura ou a mudança da rotina poderia gerar atritos e/ou desconfortos no ambiente profissional.

Outra questão importante que pode ser destacada nestes relatos em especial diz respeito à reprodução (no sentido a-crítico) da realidade social de cuidados na UTI. A adoção do referencial de assistência de Wanda Horta sugere não dar vazão à criatividade do enfermeiro, no que tange à adaptação de outros referenciais às práticas de cuidado na unidade. $\mathrm{O}$ relato de $\mathrm{E}_{1}$ aponta esse questionamento, quando nos desafia a pensar que na UTI, mesmo existindo uma oportunidade de se trazer outras contribuições externas para a contínua melhoria das práticas de saúde e de cuidado, o modelo de Wanda Horta poderia cercear o pensamento e a ação individual do enfermeiro.

Em se tratando de modelos de atendimento, a dinâmica prestação-consumo e o jogo de expectativas que nela está envolvido, orientam as concepções e práticas de saúde, assim como a forma final desse processo (as relações com o consumidor-usuário). Isso, por si só, possibilita refletir acerca das representações sobre saúde-doença, sofrimento-perturbação, assistência-cuidado e sua incorporação na dinâmica dos processos de trabalho das equipes. ${ }^{10}$

Modelos, por mais padronizados que sejam, não totalizam o conhecimento do setting de cuidados, mas nos apresentam o cenário no qual esses cuidados acontecem, de que modo e com que concepções. $\mathrm{Na}$ UTI, por exemplo, não parece clara para os enfermeiros a intenção da utilização de um modelo teórico que possa subsidiar seu trabalho, retomando sua concepção inicial de um "roteiro" prescritivo e normativo. Sendo assim, ao contrário de estimular a criatividade da equipe em torno da reinvenção cotidiana das práticas de saúde e cuidado, o modelo adotado (e deslocadamente compreendido) tende a "esterilizar" os profissionais, assumindo o controle do processo de trabalho da unidade.

Cuidar da saúde de alguém é mais que construir um objeto e um olhar de intervenção sobre ele. Para que se possa cuidar, há que se considerar a construção de projetos, há que sustentar uma consonância entre a matéria e o espírito, o corpo e a mente, moldados a partir da proposta de se opor à dissolução. A habilidade de cuidar, então, não pode resumir-se à atividade parcelar nas práticas de saúde. Deve englobar as dimensões das intersubjetividades, do controle técnico, da organização dos saberes e das práticas, da organização do processo produtivo, das 
políticas organizacionais, dos movimentos de luta pelas melhores condições técnicas e do tratamento para cuidar, expandindo-se para a totalidade das reflexões e das intervenções no campo da saúde. ${ }^{15}$

Nesse sentido, o que nos parece é que as práticas de saúde e de cuidado nas condições de atendimento intensivo e, orientadas (deslocadamente) pela metodologia da assistência de Wanda Horta, pouco têm contemplado outras dimensões da vida do sujeito, especificamente falando do cuidado e das relações que o cercam. Por isso, compreendemos que a prevalência de conhecimentos e práticas em torno do corpo do sujeito tem-se sobreposto não somente à própria proposta metodológica de Wanda Horta, mas também ao conceito de cuidado como o entendemos, ou seja, como uma relação que se estabelece para os sujeitos e entre os sujeitos, de acordo com as suas necessidades e não somente com as do profissional.

Sendo assim, é possível complementar as discussões anteriores acerca do processo de trabalho a partir dos manuais de enfermagem, que parecem contemplar uma construção teórico-instrumental na qual predominam um saber operante de características tecnológicas contraditórias, fato que se confirma diante das múltiplas concepções e funcionalidades pelos enfermeiros a partir da utilização do referencial de Wanda Horta. Por isso, o objeto de trabalho orientado pela metodologia, conforme observado, desloca-se da "necessidade do paciente" para o sistema de "queixas-conduta". Um exemplo disso é o que se verifica nas observações de campo.

Um fato que chamou atenção é que uma enfermeira registra o "subjetivo" colocando termos, de certa forma objetivos (a ela), ou seja, sob sua interpretação. Ela tem usado a comunicação não-verbal como forma de "interpretar" situações à sua maneira, e não como o paciente as vê (NO).

Ao consultar os registros do dia, nota-se que o modelo SOAP é completo, dependendo das condições do paciente no momento da evolução. Para aqueles pacientes conscientes, o "S" se resume às queixas: "Refere dor ao ser manuseado no banho de leito" (NO).

Ao avaliar os registros médicos, nota-se que todos eles são bem sucintos nas evoluções, que seguem os moldes do SOAP. As avaliações apresentam os diagnósticos confirmados, bipóteses e intercorrências do plantão. As avaliações de enfer- magem continuam confusas, cada um escrevendo e avaliando diferentemente dos demais (NO).

Ao analisar as concepções tecnológicas das práticas de saúde em Centros de Saúde de São Paulo, destacou-se, que os registros dos profissionais seguem um padrão objetivo com poucas linhas que, designam as informações de caráter altamente discriminador no sentido clínico, que parecem mais postas como defesa, e não como estímulo. A estruturação do próprio atendimento pessoal das equipes tem sido direcionada para o sistema de "queixas" como se estas fossem o sentido e o significado do modo de organizar o trabalho. Isso corresponderia à manutenção de um modelo clínico que tem dado conta de explicar as condutas a partir das queixas dos clientes e nada mais do que isso. ${ }^{16}$

Toda sociedade deveria superar as concepções passionais e elementares, que compõem grande parte do senso comum ${ }^{\dagger}$, produzindo saberes e ações coerentes, resultantes da vontade coletiva em ato, ou seja, produzindo bom senso. A multiplicidade de formas de pensamento pode-se manifestar na retomada de uma contradição teórico-conceitual a que os homens estão expostos, no processo de viver. Isso pode criar contradições no pensamento que interferem na sua prática, na sua própria vida, além de se manifestarem no locus social. ${ }^{8}$

A análise da última nota de observação, em especial, revelou-nos outra preocupação. Os vários formatos de redação refletem as múltiplas maneiras de pensar dos enfermeiros e tornam os registros de enfermagem diferentes dos registros dos médicos, em conteúdo e precisão. Pelo que pudemos notar os registros médicos sempre eram concisos, representando as necessidades mais imediatas das pessoas internadas naquele momento em especial. Ao passo que os registros dos enfermeiros, pareceram-nos confusos, dispondo informações de maneira aleatória. Um exemplo disso é apresentado a seguir sobre a avaliação de um mesmo paciente, que foi tirado das notas de observação em campo.

Avaliação médica: sem mudança no quadro neurológico (mesmo com diminuição de Sódio). Quadro pulmonar inalterado, tendência à hipertensão. Apresentou pico febril pela manhã. Glicemias elevadas, necessitando de Insulina Regular EV.

\footnotetext{
$\dagger$ O senso comum compreende um conjunto de concepções de mundo que não são únicas, idênticas no tempo e no espaço, mas correspondem ao conhecimento reunido de maneira desorganizada, desagregada, dispersa, assumindo um caráter acrítico e a-filosófico, que perpassam a bistória, a vida social e cultural, onde se desenvolve a individualidade moral do homem. Embora o senso comum carregue concepcões individualizadas e pouco reflexivas da vida humana, elas já podem caracterizar-se como o embrião de uma nova concepsão de mundo, porque estimulam a reflexão e o repensar das idéias. ${ }^{8}$
}

Texto Contexto Enferm, Florianópolis, 2007 Out-Dez; 16(4): 703-11. 
Avaliação dos enfermeiros: sem informaçoes no formato $\operatorname{SOAP}\left(\mathrm{E}_{1}\right)$.

Desobstrução ineficaz das vias aéreas caracterizado pela incapacidade de remover as secreções das vias aéreas (brônquios e alvéolos) ( $\left.\mathrm{E}_{2}\right)$.

Contra-indico aplicașão subcutânea abdominal devido à coleção local. Continua não suportando mudança de decúbito, com massagem de conforto eficaz $\left(E_{3}\right)$.

Necessidade de oxigenação melhorada, extubado pela manhã, mantendo-se em macronebulização $\left(E_{4}\right)$.

Sem informacōes no formato $\operatorname{SOAP}\left(\mathrm{E}_{5}\right)$.

Bom padrão respiratório em PS (Pressão de Suporte). Mantém muita secreşão traqueal, dificultando a entubaşão $\left(E_{0}\right)$.

Claro que é preciso relativizar esta última observação de campo, que, dialeticamente, nos oferece mais de uma interpretação possível. Percebemos que a disposição de distintas formas de redação pode manifestar as múltiplas formas de pensar e de fazer do enfermeiro, compartilhadas e materializadas nesse sentido. Exemplo disso diz respeito, primeiramente, à forma de preenchimento dos campos. $\mathrm{E}_{1}$ e $\mathrm{E}_{5}$, por exemplo, não seguem as orientações do modelo orientado para o problema no prontuário. No caso de $E_{2}$, as informações são dispostas na forma de diagnósticos de enfermagem, outra metodologia de assistência que não faz parte da rotina cotidiana de cuidados na UTI. Sendo assim, é possível observar a existência de uma diversidade de caracterizações tecnológicas no processo de trabalho da enfermagem na UTI. Especialmente quando cada sujeito possui uma concepção particularizada que mesmo que reproduza uma linguagem técnica comum a todos pouco levanta as condições do sujeito por inteiro, à medida que explora "parcelas" deste e não um conteúdo substantivo totalizador.

A enfermagem produz, diariamente, muitas informações resultantes de suas ações de cuidado diretas ou indiretas aos pacientes. É possível estimar que mais de $50 \%$ das informações dos prontuários sejam geradas pela enfermagem. Entretanto, a gama de informações vem crescendo em uma proporção que, por vezes, foge à capacidade de organização do próprio enfermeiro sobre os registros que produz. Nesse sentido, a compilação de tais informações tem-se tornado ineficiente para o gerenciamento do cuidado e para a tomada de uma decisão racional e objetiva, por parte dos enfermeiros. As anotações feitas por eles, na maioria das vezes, são inconsistentes, ilegíveis e subjetivas, não havendo uma definição metodológica estruturada. ${ }^{17}$
Finalmente, pode-se concluir que o espaço social da terapia intensiva parece criar uma oportunidade ímpar não somente de discutir dialeticamente as práticas de saúde a partir dos saberes operantes dos sujeitos que as prestam, mas de compreender como essa prática - e seus instrumentos adequados - produzem e reproduzem efeitos e deslocamentos no cotidiano assistencial dos serviços e nas relações entre os sujeitos.

\section{CONSIDERAÇÕES FINAIS}

Percebemos que o processo de trabalho nessas unidades, refletido na força de trabalho das equipes multiprofissionais, parece velar que, por traz do "doente" (como concepção básica do modelo médico hegemônico em saúde), existe um "ser doente", que tem carecimentos e problemas específicos. Isso pôde ser visualizado nas diferentes contextualizações obtidas pela análise dialética dos registros e da metodologia de assistência de Wanda Horta, enquanto instrumentos do processo de trabalho da enfermagem na UTI.

Observamos que as práticas de saúde nas condições de atendimento intensivo naturalmente compreendem um conjunto de variáveis tecnológicas direcionadas às atividades parcelares, fragmentadas e com pouco (ou nenhum) sentido totalizador. Assim sendo, fica evidente que o processo de trabalho dos profissionais na terapia intensiva seja imbuído de saberes e práticas de cuidado que se situem nessas condições, com predomínio de dispositivos produzidos/adquiridos pela evolução da ciência e pouco nas relações entre os sujeitos.

É possível, a partir deste estudo, ainda tecer comentários acerca da necessidade de possibilitar a constante transformação do contexto assistencial e dos processos de trabalho a partir de suas distintas dimensões tecnológicas, associando o cuidado ao corpo ao cuidado do sujeito, que possui necessidades específicas e que devem ser por princípio, o início, meio e fim desse mesmo processo de trabalho, sem desigualdades ou verticalizações.

\section{REFERÊNCIAS}

1 Souza LNA. A interface da comunicação entre enfermagem e as(os) clientes em uma Unidade de Terapia Intensiva [dissertação]. Florianópolis (SC): UFSC/PEN; 2000.

2 Nascimento ERP. Acolhimento no espaço das relações na unidade de terapia intensiva [tese]. Florianópolis (SC): UFSC/PEN; 2003. 
3 Cassel J. Stories, moral judgment, and medical care in an intensive care unit. Qualitative Health Research. 2004 May; 14 (5): 663-74.

4 Silva Júnior AG. Modelos tecnoassistenciais em saúde: o debate no campo da saúde coletiva. São Paulo (SP): Hucitec; 1998.

5 Foucault M. Microfísica do poder. 19a ed. São Paulo(SP): Graal; 2004.

6 Kreutz I, Gaiva MAM, Azevedo RCS. Determinantes sócio-culturais e históricos das práticas populares de prevenção e cura de doenças de um grupo cultural. Texto Contexto Enferm. 2006 Jan-Mar; 15 (1): 89-97.

7 Marx K, Engels F. A ideologia alemã. São Paulo (SP): Martins Fontes; 1989.

8 Gramsci A. Concepção dialética da história. 10a ed. Rio de Janeiro (RJ): Civilização Brasileira; 1995.

9 Engels F. Sobre o papel do trabalho na transformação do macaco em homem 1952 [acesso em 2006 Dez 10]. Disponível em: http://www.ebooksbrasil.org/ eLibris/macaco.html

10 Merhy EE. Em busca do tempo perdido: a micropolítica do trabalho vivo em saúde. In: Merhy EE, Onocko $\mathrm{R}$, organizadores. Agir em saúde: um desafio para o público. São Paulo (SP): Hucitec; 2006. p.71-112.
11 Chizzotti A. Pesquisa em ciências humanas e sociais. São Paulo (SP): Cortez; 1991.

12 Giovanni G. O método dialético. In: Anais do 3o Seminário Nacional de Pesquisa em Enfermagem, 1984 Abr 3-6; Florianópolis, Brasil. Florianópolis (SC): ABEn - Seção SC; 1984. p.161-71.

13 Ministério da Saúde (BR), Conselho Nacional de Saúde, Comissão Nacional de Ética em Pesquisa. Resolução No 196 de 10 de outubro de 1996: diretrizes e normas regulamentadoras de pesquisa envolvendo seres humanos. Brasília (DF): MS; 1996.

14 Horta W. Processo de enfermagem. São Paulo (SP): EPU; 1979.

15 Ayres JRCM. Sujeito, intersubjetividade e práticas de saúde. Ciência Saúde Coletiva. 2001 Jan-Jun; 6 (1): 63-72.

16 Gonçalves RBM Tecnologia e organização social das práticas de saúde: características tecnológicas do processo de trabalho na rede estadual de centros de saúde de São Paulo. São Paulo (SP): Hucitec/Abrasco; 1994.

17 Santos SR, Paula AFA, Lima JP. O enfermeiro e sua percepção sobre o sistema manual de registro no prontuário. Rev. Latino-Am. Enfermagem. 2003 JanFev; 11 (1): 80-7. 